\title{
Two more cases of sparganosis from Sri Lanka
}

\author{
A S Dissanaike', P R Anthonis ${ }^{2}$, A H Sheriffdeen ${ }^{3}$, R L Ihalamulla ${ }^{4}$ and N D Karunaweera ${ }^{4}$
}

The Ceylon Journal of Medical Science 2001; 44: 19-22

\section{Summary}

Two plerocercoid larvae probably of Spirometra $s p$, were recovered from the anterior abdominal wall of two patients in Colombo, Sri Lanka. Recently two other such infections, were reported in tissue sections bringing the total number of reported cases of sparganosis from Sri Lanka to four.

Key words: Sparganosis, Sri Lanka, human infection

\section{Introduction}

Two cases of subcutaneous sparganosis probably caused by plerocercoids of Spirometra sp. were reported recently from Sri Lanka (1). These were seen in tissue sections of subcutaneous lumps in the right groin and left upper arm respectively. We now report two entire plerocercoid larvae one of which was alive - from the anterior abdominal wall of patients in Sri Lanka. These would be the third and the fourth cases of sparganosis from this country.

\section{Case reports}

\section{Case 1}

In August 1999, a 40.year old male from Pannagomuwa, Lakehaliya, in the Kurunegala District of the North Western Province of Sri Lanka, presented with a painful tender lump of about 5 years duration in the anterior abdominal wall. One of us (PRA) examined the patient, made a preliminary diagnosis of an omental protuberance from a paraumbilical hernia and performed surgery on him after preliminary investigations.
Haemoglobin $14 \mathrm{~g} / \mathrm{dL}$

W.B.C was $7.2 \times 10^{9} / \mathrm{L}$ Neutrophils $46 \%$, Lymphocytes $46 \%$, Eosinophils $8 \%$.

A barium enema showed no abnormality.

Under general anaesthesia an ovoidal subcutaneous granuloma was dissected out. It was in the left paraumbilical area with a length of $10 \mathrm{~cm}$ anteroposteriorly and a width of $8.7 \mathrm{~cm}$. The maximum thickness in the middle was $2 \mathrm{~cm}$ and it had not penetrated the underlying muscle. From the middle of the granuloma a live flat worm crept out and was further examined at the Department of Parasitology. Unfortunately the granuloma was inadvertently discarded and it was not possible to study the tissue reaction around the larva. There was no evidence of a hernia.

\section{Description of the worm}

The worm is a larval cestode with pseudo-segmentation and showing a 'subtle invagination' at the broad anterior end, which represents the scolex as mentioned by Kron et al, 1991(2). It is $22 \mathrm{~mm}$ long with a maximum width of $1.1 \mathrm{~mm}$ at the anterior end. Sections taken from the middle of the larva show the typical thick cestode cuticle, subcuticular cells and parenchymatous tissue filling the whole space in which are embedded pseudophyllid type longitudinal muscle strands and thin walled excretory ducts as described by Andersen, 1983 (3) (Fig.2). Only a few scattered calcareous corpuscles with concentric rings are seen in some sections. It is identified as a plerocercoid larva (sparganum) of Spirometra sp. 


\section{Case 2}

This case was that of a 23 year old female from Bandaragama in the Kalutara District, Western Province of Sri Lanka. This patient who was first seen by one of us (PRA) was referred to the national Hospital of Sri Lanka. She presented with a migratory lump of 4 months duration associated with pain in the anterior abdominal wall, to the left of the umbilicus. She also complained of fever nausea, and loss of appetite for the same period.

Haemoglobin $6.2 \mathrm{~g} / \mathrm{dL}$

WBC was $5.6 \times 10^{9} /$ L Neutrophils $66 \%$, Lymphocytes $24 \%$, Eosinophils $8 \%$, Monocytes $2 \%$

ESR $10 \mathrm{~mm} 1^{\text {st }} \mathrm{hr}$

Surgery was performed by one of us (AHS) under general anaesthesia and a longitudinal incision made over the lump revealed a mass of fibrous and fatty tissue. It was in the left paraumbilical area and somewhat oval in shape, $3 \mathrm{~cm}$ long and $2 \mathrm{~cm}$ wide. When the mass of tissue was opened up a whitish, thread like worm unfurled. It was sent to the Department of Parasitology for identification.

\section{Description of the worm}

The worm is $27.4 \mathrm{~mm}$ long with a width of $1.3 \mathrm{~mm}$ at the broad anterior end (Fig.1 and 3). $\mathrm{H} \& \mathrm{E}$ stained transverse sections of this end show bothrial slits (Fig. 4). It is also identified as a sparganum of Spirometra sp. for the same reasons as in case 1 (Fig. 5).

A portion of the posterior end of the worm was embedded in the mass of tissue. Stained transverse sections show the host tissue reaction around it. Dense infiltration by inflammatory cells such as lymphocytes, neutrophils, eosinophills and macrophages are seen. This process has spread to the integument and the parenchyma of the dead tissue of the worm to some extent. Characteristic fat cells are seen in the surrounding host tissue (Fig. 6)

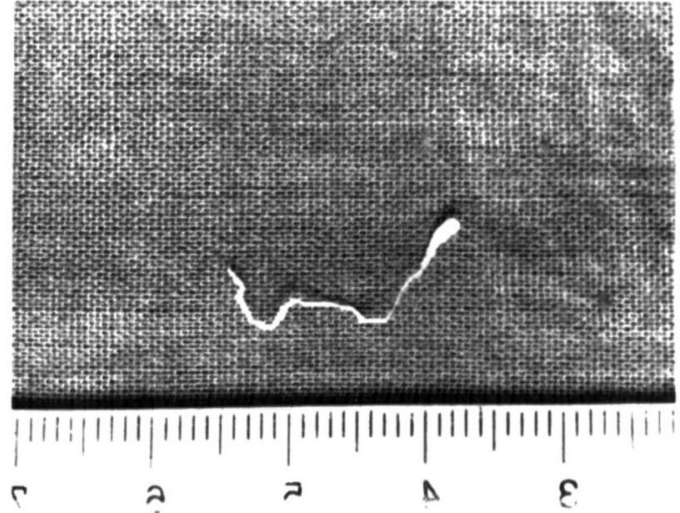

Fig 1: Entire larva; scale mm - case 2.

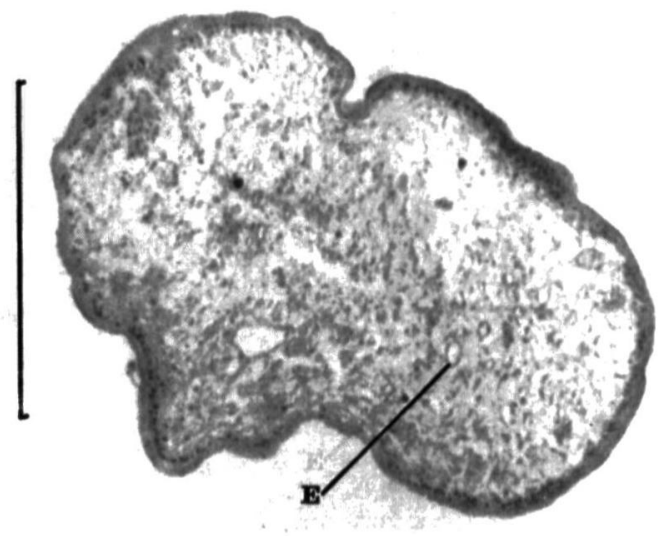

Fig 2: T.S. middle portion of larva showing excretory ducts $(E)$ - case $1($ Bar $=300 \mu \mathrm{m})$

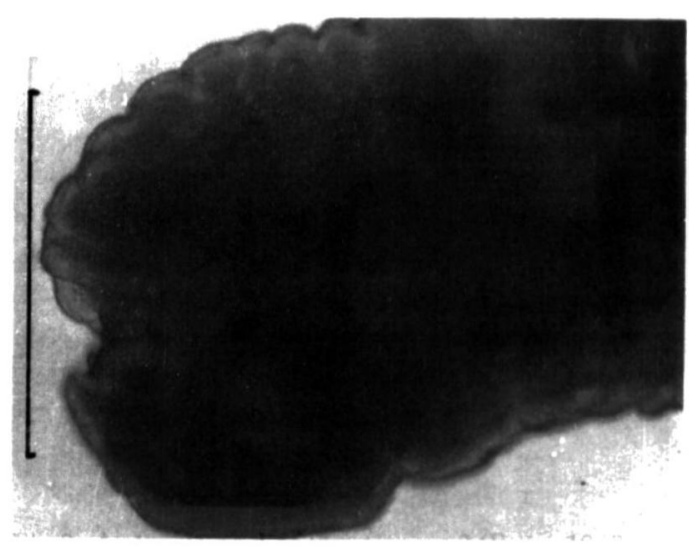

Fig 3: Anterior end of larva - case $2(B a r=1000 \mu \mathrm{m})$ 


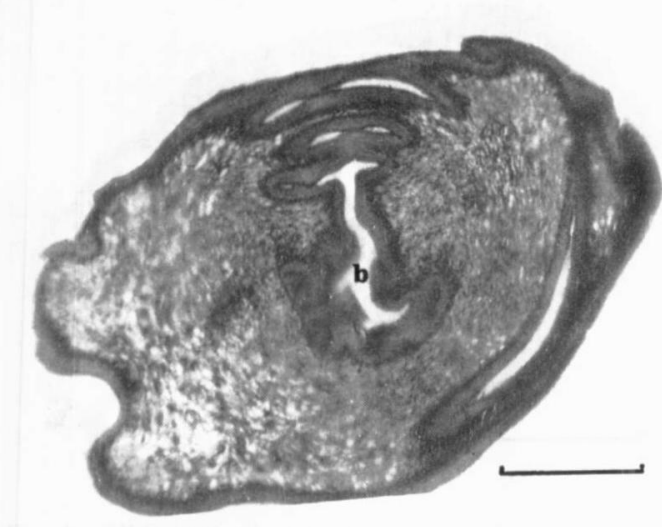

Fig 4: T.S. anterior end of larva showing bothrial slits $(\mathrm{b})$ - case $2(\mathrm{Bar}=200 \mu \mathrm{m})$

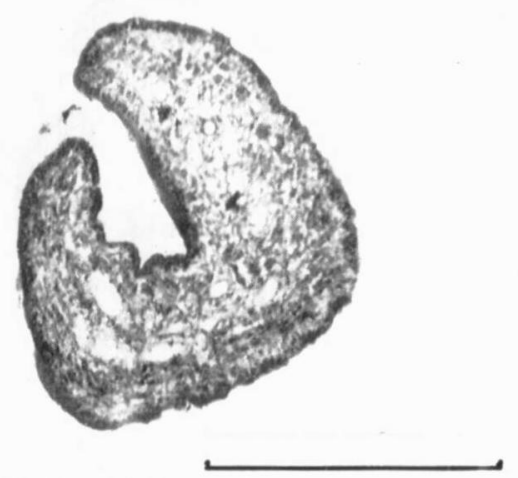

Fig 5: T. S. middle portion of larva - case 2 $($ Bar $=300 \mu \mathrm{m})$

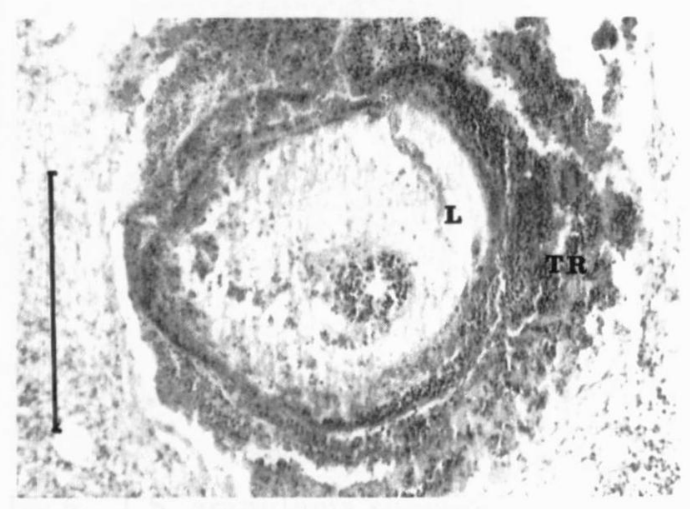

Fig 6: T.S. granuloma showing host tissue reaction (TR) and larva (L) - case 2 $($ Bar $=300 \mu \mathrm{m})$

\section{Discussion}

In the previous reports of sparganosis from Sri Lanka (1) it was suggested that the larvae, seen in tissue sections were probably plerocercoids of Spirometra erinacei. This cestode had been reported in Sri Lanka from dogs (4). That report included a review of the literature and a discussion on the probable mode of infection (1). It was suggested that water containing procercoids in infected Cyclops, accidentally swallowed, was the cause of infection. There was no history of eating raw flesh of paratenic hosts nor was there evidence of application of poultices from such hosts. In the present cases too there was no history of consumption of flesh of paratenic hosts or of the application of poultices.

That fact that in the first case the worm was still alive despite a 5 year history stresses the importance of early removal of the sparganum to minimize the risk of invasion of vital tissue by migrating larvae.

We report these cases to focus attention on the fact that even in a country like Sri Lanka where raw flesh is seldom if ever consumed infections of this type can and do occur probably by ingestion of an infected Cyclops. An awareness of this zoonotic infection will no doubt lead to more and more cases being reported in the future.

\section{Acknowledgements}

We are grateful to Professor L. R. Amarasekara, Department of Pathology, Faculty of Medicine for providing facilities for sectioning and photomicrography; we also thank the following for technical support: Mrs. Himali Gunatilaka, Mr. P. Gamage. Mr K. H. Weerasena and Mrs. Kumudini Wickramathanthri, Department of Parasitology and Mrs. R. A. Badra Dissanayake and Mr. R. A. A. N. Ranawaka of the Photography Unit of the Faculty of Medicine, University of Colombo.

\section{References}

1. Wijesundera M DeS, Ratnatunga N, Kumarasinghe MP and Dissanaike A S. First reports of subcutaneous sparganosis in Sri Lanka. Ceylon Medical Journal 1997; 42: 30-32. 
2. Kron M A, Guderian R, Guevara $A$ and Hidalgo A. Abdominal sparganosis in Ecuador: a case report. American Journal of Tropical Medicine and Hygiene 1991; 44: 146150.

3. Andersen K I. Description of musculature differences in spargana of Spirometra (Ces- toda; Pseudophyllidea) and tetrathyridia of Mesocestoides (Cestoda; Cyclophyllidea) and their value in identification. Journal of Helminthology 1983; 57: 331-334.

4. Seneviratna $P$ and Mahalingam S. Some helminths hitherto not reported fron' Ceylon. Ceylon Veterinary Journal 1962; 10: 88-92. 